\title{
RANCANG BANGUN PROTOTYPE ALAT PENDETEKSI TINGKAT KEKERUHAN DAN MENGUKUR DEBIT AIR PADA KOLAM LELE MENGGUNAKAN ARDUINO UNO
}

\author{
Rio Dwi Heri Kristianto ${ }^{1}$ \\ Program Studi Teknik Elektro, Fakultas Teknik, Universitas Panca Marga \\ Email: riodwiherikristianto@gmail.com \\ Ira Aprilia ${ }^{1}$ \\ Program Studi Teknik Elektro, Fakultas Teknik, Universitas Panca Marga \\ Email: ira.aprilia11@upm.ac.id \\ Dyah Ariyanti ${ }^{1}$ \\ Program Studi Teknik Elektro, Fakultas Teknik, Universitas Panca Marga \\ Email: dyahariyanti@upm.ac.id
}

\begin{abstract}
Catfish cultivation activities have become the livelihood of most communities. There are also communities that make catfish ponds as side businesses, some make fish ponds as fishing ponds and some that make catfish ponds because of the hobby of the community. In catfish ponds there are several things to be aware of, among others, water quality and drainage in ponds, where catfish growers pay less attention to the quality of water in the pond so that fish production becomes decreased and also water drainage in the water filling is still done manually. So in this study has been made a noise level detection tool and measuring the volume of water using Light Dependent Resistor (LDR) sensor and Ultrasonic sensor, where the LDR sensor as a meter of turbidity level. When the LDR sensor detects the noise then the water will be drained. And ultrasonic sensors as a water volume gauge that will serve to detect the volume of water when the water is drained and when filling water. The system uses the Arduino Uno microcontroller as a controller of the LDR sensor and the Ultrasonic sensor. The test percentage reached $85.71 \%$, and the readings of the LDR sensor murky water $>110$, medium water 70-100, and clear water 40-60. While ultrasonic sensor readings the maximum water volume limit is 16.5 liters and the minimum water volume limit is 3 liters. This test is carried out on the aquarium.
\end{abstract}

Keywords : Arduino Uno, WaterBidity, LDR Sensor, Ultrasonic Sensors.

\begin{abstract}
ABSTRAK: Kegiatan budidaya ikan lele sudah menjadi mata pencaharian sebagian besar masyarakat. Ada juga masyarakat yang menjadikan kolam ikan lele sebagai usaha sampingan, ada juga yang menjadikan kolam ikan sebagai usaha tempat pemancingan dan ada juga yang menjadikan kolam ikan lele karena hobby dari masyarakat. Pada kolam lele terdapat beberapa hal yang harus diperhatikan antara lain, kualitas air dan pengurasan pada kolam, dimana pembudidaya lele kurang memperhatikan kualitas air pada kolam sehingga produksi ikan menjadi menurun dan juga pengurasan air pada pengisian air masih dilakukan secara manual. Maka pada penelitian ini telah dibuat alat pendeteksi tingkat kekeruhan dan mengukur volume air yang menggunakan sensor Light Dependent Resistor (LDR) dan sensor Ultrasonik, sensor LDR ini sebagai pengukur tingkat kekeruhan. Ketika sensor LDR mendeteksi kekeruhan maka air akan terkuras. Dan sensor Ultrasonik sebagai pengukur volume air yang akan berfungsi mendeteksi volume air disaat air terkuras dan disaat pengisian air. Sistem ini menggunakan mikrokontroler Arduino Uno sebagai pengontrol dari sensor LDR dan sensor Ultrasonik. Presentase uji coba yang dilakukan mencapai 85.71\%, dan hasil pembacaan sensor LDR air keruh > 110, air sedang 70-100, dan air jernih 40-60. Sedangkan hasil pembacaan sensor Ultrasonik batas maksimal volume air 16,5 liter dan batas minimal volume air 3 liter. Pengujian ini dilakukan pada akuarium.
\end{abstract}

Kata kunci : Arduino Uno, Kekeruhan air, Sensor LDR, Sensor Ultrasonik.

\section{PENDAHULUAN}

Tkan lele merupakan salah satu hewan yang dibudidayakan oleh sebagian besar masyarakat sebagai

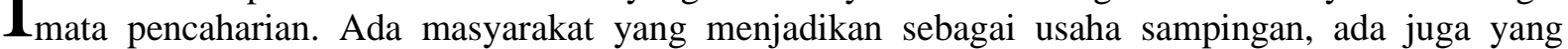
menjadikan tempat pemancingan dan ada juga yang karena hobby untuk memelihara ikan lele. Pada kolam budidaya ikan lele, perlu diperhatikan kondisi air kolam. Kondisi air yang tidak memenuhi syarat bisa jadi sarang penyakit yang berbahaya untuk pertumbuhan ikan lele [1].

Masalah yang sering dialami pada kolam adalah bau busuk pada air kolam. Akibat dari bau air kolam yang dialami dapat mengganggu pemilik kolam, dan masyarakat sekitar. Bahkan ada juga yang merasa tidak suka pada ikan lele dikarena habitan hidup lele yang bau dan kotor. Oleh sebab itu perlu untuk mengatur kualitas air yang baik agar air tidak berbau. Bau pada kolam disebabkan oleh kotoran ikan dan pergantian air yang tidak teratur. Ikan lele kondisi air yang keruh dan bau mampu bertahan hidup karena lele mempunyai alat pernafasan berupa arborescent namun jika terlalu kotorpun tidak baik bagi ikan oleh karena itu perlu untuk mengganti air. Hal tersebut terjadi adanya kotoran atau sisa makanan ikan

\footnotetext{
${ }^{1}$ Program Studi Teknik Elektro, Fakultas Teknik, Universitas Panca Marga
} 
yang mengendap dan menumpuk didasar kolam dan air manjadi bau. Oleh sebab itu sangatlah penting untuk mengganti air dengan cara berkala dan teratur. Pemberian pakan yang sesuai sangat perlu diperhatikan agar pakan habis dimakan oleh ikan dan tidak tersisa pada kolam. Ikan lele mempunyai nafsu makan yang besar akan tetapi kalau berlebihan ikan lele akan mengeluarkan makanan kembali jika mengalami stres. Dan sisa makanan inilah salah satu penyebab kolam menjadi bau [2].

Secara umum proses mengganti air kolam lele dilakukan secara manual dengan cara mengganti air yang kotor secara langsung oleh pembudidaya. Namun cara tersebut kurang efektif karena beberapa masyarakat menjadikan budidaya lele ini untuk pekerjaan sampingan dari pekerjaan utama. Bagi pembudidaya ikan lele yang mempunyai kolam yang banyak, akan mengalami kesulitan dalam mengganti air yang kotor [3].

Mengatasi masalah tersebut dalam proyek ini dirancang subuah sistem menguras air menggunakan selenoid vakve dan mengisi air menggunakan pompa air dimana alat ini akan otomatis menguras dan mengisi air pada kolam lele, maka diperlukan sebuah sistem dimana yang bisa memantau tingkat kekeruhan air dengan menggunakan sensor light dependent resistor (LDR), serta sensor ultrasonik untuk memantau volume air kolam lele, sistem ini lebih mudah dirancang karena LDR dan Ultrasonik mudah didapatkan. Dimana LDR merupakan salah satu jenis resistor yang tergantung dari intensitas cahaya untuk menghasilkan nilai resistansi. Nilai resistansi yang diterima oleh LDR digunakan untuk mengukur tingkat kekeruhan air [4].

Air yang keruh akan menyebabkan berkurangnya intensitas cahaya yang diterima oleh sensor. Hal ini disebabkan oleh cahaya yang melintasi air akan mengalami penyerapan atau pemantulan, sehingga intensitas cahaya yang dapat diteruskan jumlahnya terbatas. Sensor yang bisa mengetahui intensitas cahaya, yaitu sensor LDR. Sensor LDR dapat membantu mengetahui kekeruhan yang ada pada air kolam lele, jika kekeruhan air terdeteksi maka dilakukan pengurasan air kolam dengan cara otomatis. Sensor ultrasonik digunakan sebagai alat mengukur batas minimal dan maksimal volume air untuk pengurasan dan pengisian air kolam [5], [6].

Berdasarkn persoalan tersebut penulis tertarik untuk membuat perancangan alat dengan pengendalian menggunakan atau berbasis Arduino Uno. Alat ini menggunakan sensor LDR sebagai mendeteksi kekeruhan pada kolam lele, serta menggunakan sensor Ultrasonik untuk mengukur batas pengisian air pada kolam. Dalam perancangan ini penulis menggunakan dua selenoid, satu di tempat penampung air dan satu di kolam agar dalam pengisian bisa berjalan dengan otomatis dengan adanya mikrokontroler yang dapat digunakan sebagai pengendali proses.

\section{METODE PENELITIAN}

Metode yang digunakan untuk mengumpulkan data dan informasi dalam penelitian ini sebagai berikut (lihat Gambar 1):

1. Observasi

Observasi meupakan tahapan awal dalam melakukan penelitian. Observasi dilakukan dengan cara mengamati dan meneliti perkembangan teknologi pada saat ini. Dengan observasi ini, diharapkan penulis memahami terhadap objek yang akan diteliti sehingga dapat menentukan tahapan yang akan dilakukan dalam penelitian. Objek pada penelitian yang dilakukan adalah tingkat kekeruhan dan volume air pada kolam ikan.

2. Studi Literatur

Berdasarkan permasalahan yang dirumuskan, penulis melakukan studi literatur. Studi literatur merupakan proses yang dilakukan untuk menelusuri, mencari dan menghimpun informasi yang relavan dengan penelitian yang dilakukan 


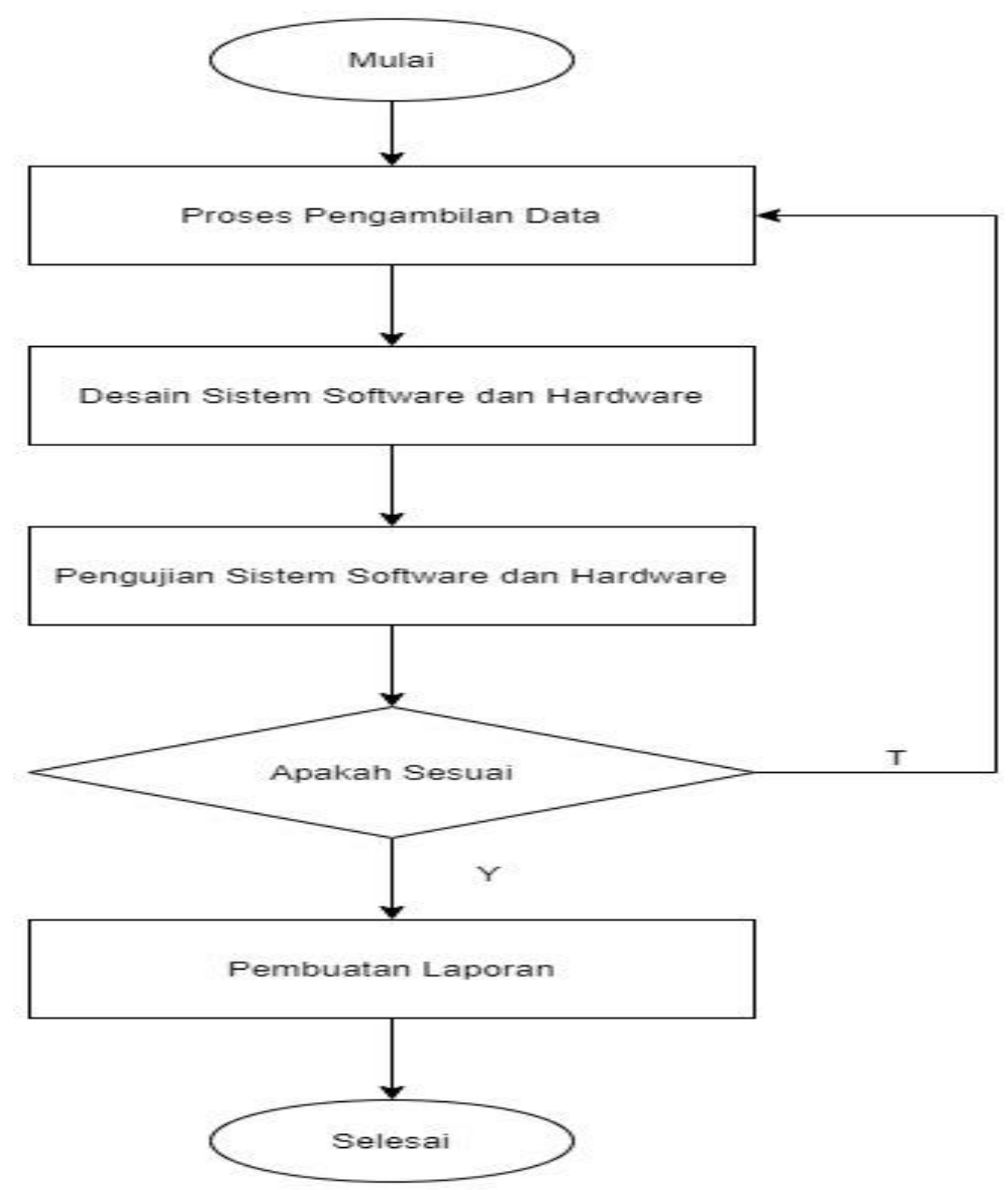

- Gambar 1. Diagram Alir Penelitian

\section{Desain Sistem Software dan Hardware}

Desain hardware merupakan kerangka bentuk atau rancangan dari perangkat keras yang digunakan untuk membangun sistem. Desain hardware menggunakan diagram blok, seperti pada Gambar 2, desain sistem alat seperti pada Gambar 3.

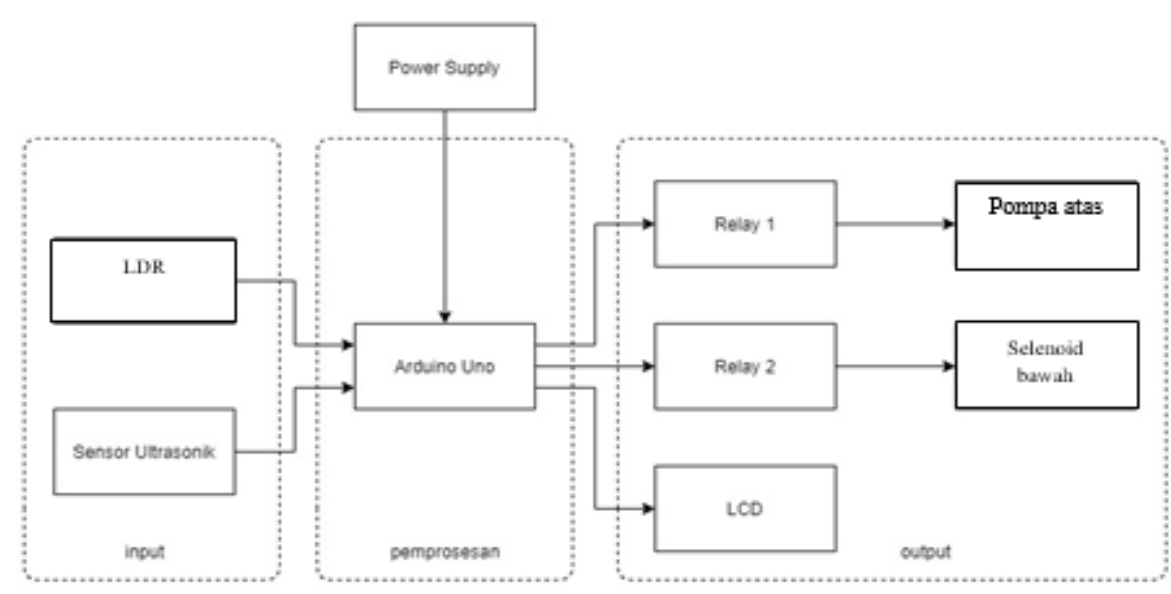

Gambar 2. Diagram Blok Rangkaian 


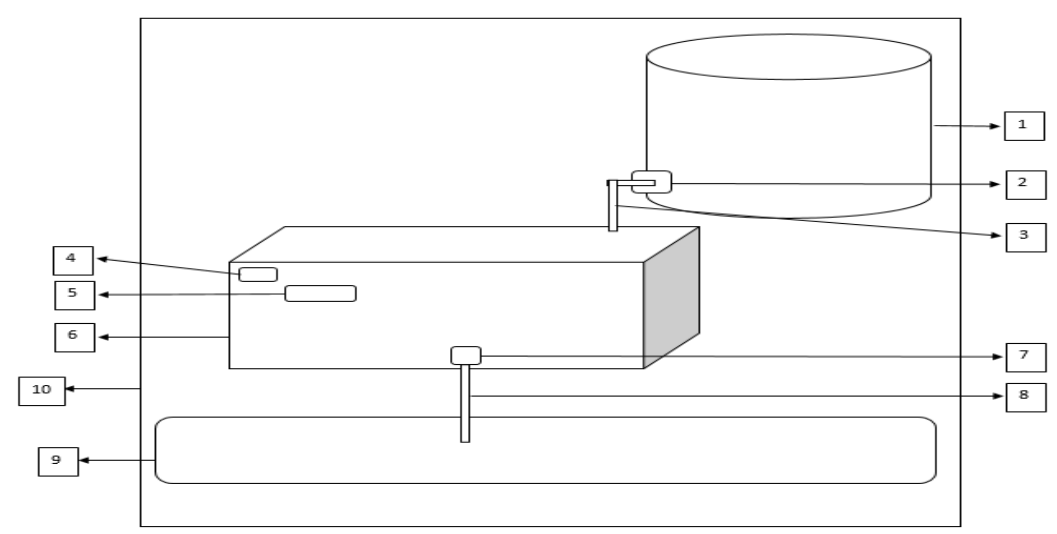

Gambar 3. Desain Sistem Alat

Keterangan :

1. Bak penampung air

2. Pompa Atas

3. Pipa penghubung aliran air

4. Sensor Ultrasonik

5. Sensor Light Dependent Resistor (LDR)

6. Kolam ikan (Akuarium)

7. Selenoid Bawah

8. Pipa penghubung aliran air

9. Bak pembuangan air

10.Rak / kesing

Desain software dan hardware merupakan tahapan sebelum membangun suatu sistem. Desain software merupakan kerangka bentuk atau rancangan perangkat lunak yang berfungsi sebagai gambaran untuk memperudah dalam membangun suatu sistem. Desain software yang akan dibangun menggunakan diagram alir, seperti pada Gambar 4. 


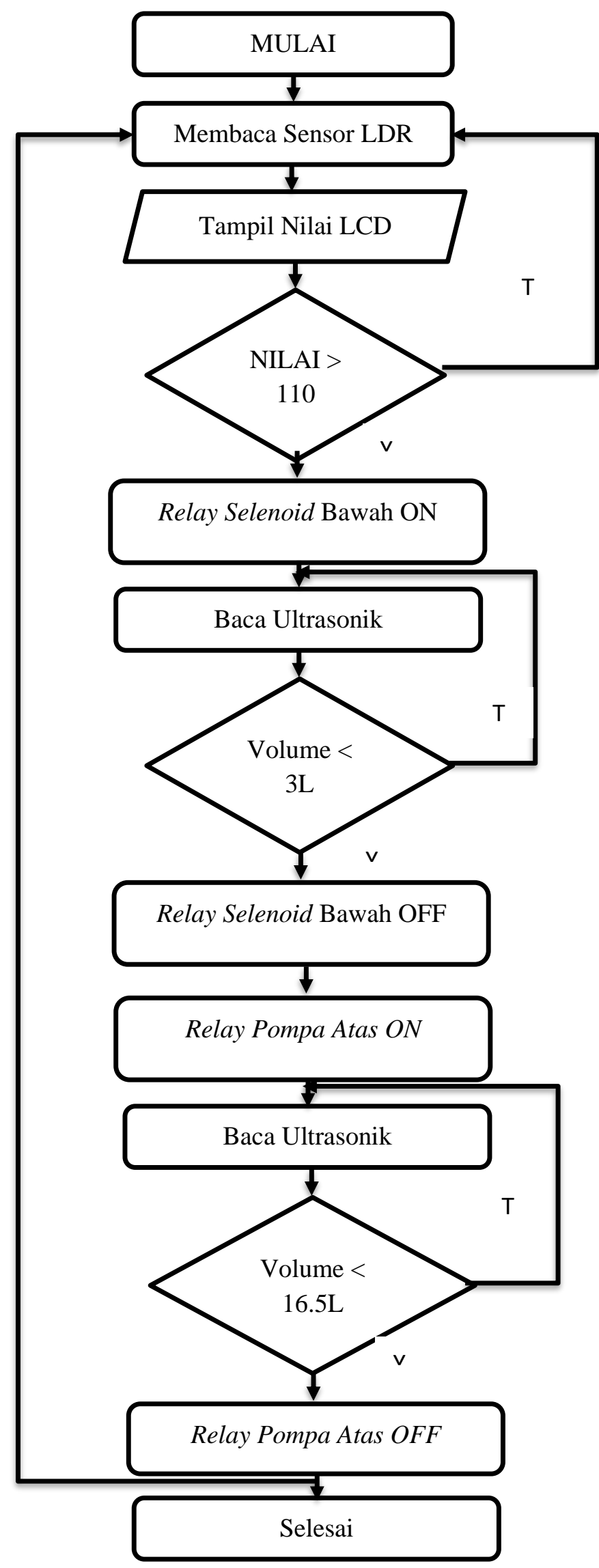

Gambar 4. Diagram Alir Sistem 


\section{Implementasi Sistem}

\section{HASIL PENELITIAN DAN PEMBAHASAN}

Dengan menerapkannya sistem prototip alat pendeteksi tingkat kekeruhan dan mengukur debit air pada kolam ikan lele menggunakan mikrokontroler arduino agar memudahkan para pekerja untuk memantau kekeruhan air dan debit air pada kolam lele. Gambar 5, merupakan rangkaian sistem yang ada pada sistem prototip alat pendeteksi tingkat kekeruhan dan mengukur debit air pada kolam ikan lele menggunakan mikrokontroler arduino.

Sensor Cahaya LDR digunakan sebagai mendeteksi nilai kekeruhan air, sensor yang dapat mengalami perubahan resistansinya apabila mengalami perubahan pada saat penerimaan cahaya, Tabel 1 menunjukkan konfigurasi Pin arduino dengan LDR.

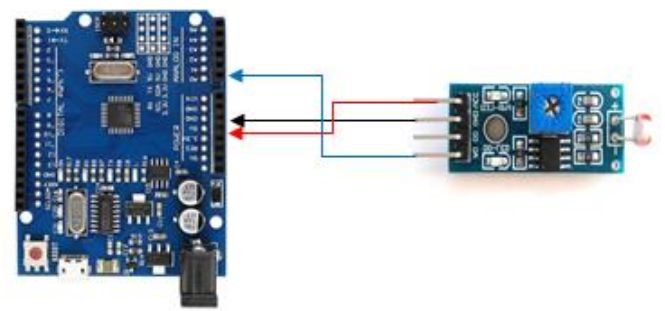

Gambar 5. Rangkaian Arduino Uno dan LDR

Tabel 1 Konfigurasi Pin Arduino dengan LDR

\begin{tabular}{ll}
\hline Arduino Uno & Sensor LDR \\
\hline Pin A0 & AO \\
$5 \mathrm{~V}$ & VCC \\
GND & GND \\
\hline
\end{tabular}

\section{Sensor Ultrasonik}

Sensor ultrasonik pada sistem ini (Gambar 6) digunakan sebagai pembaca jarak yang berfungsi untuk mengukur volume air. Dalam perancangan sensor ultrasonik ini masih memerlukan perangkat lain yang berfungi untuk membaca volume air, Tabel 2, menunjukkan konfigurasi pin Arduino dengan Ultrasonik

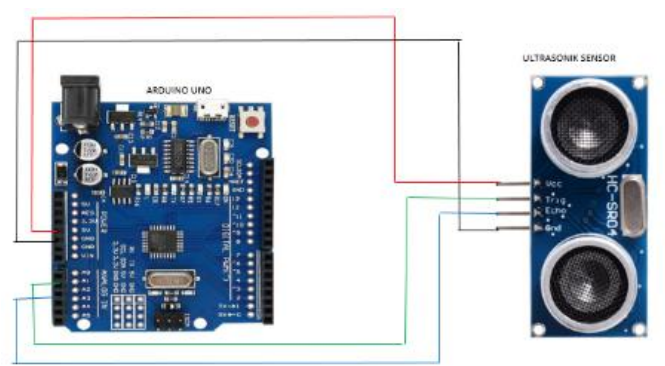

Gambar 6. Rangkaian Arduino dan Ultrasonik

-

- Tabel 2._Konfigurasi Pin Arduino dengan Ultrasonik

\begin{tabular}{ll}
\hline Arduino Uno & Sensor Ultrasonik \\
\hline GND & GND \\
$5 \mathrm{~V}$ & VCC \\
Pin A1 & TRIG \\
A2 & Echo \\
\hline
\end{tabular}

\section{Liquid Cristal Display (LCD) 16x2}

Banyaknya pin Input dan Output yang terdapat pada LCD 16 x 2 maka dibutuhkan sebuah modul yang dapat digunakan untuk menyederhanakan pin LCD 16 x 2 yaitu modul I2C. Dari 16 pin Input dan Output pada LCD $16 \times 2$ dapat disederhanakan menjadi empat pin yaitu VCC, GND, SDA dan SCL. Modul I2C memerlukan tegangan sebesar 5V yang disuplai dari Arduino melalui pin VCC dan pin GND 
sebagai grounding. SDA (Serial Data) adalah pin yang berguna sebagai jalur pengiriman data. Sedangkan SCL (Serial Clock) berguna sebagai jalur clock. Pada Arduino sudah tersedia pin SDA dan pin SCL, tidak seperti Arduino Uno yang belum tersedia. Namun sama seperti Arduino Uno yang memanfaatkan pin A 4 dan A 5 sebagai pin SDA dan SCL, pin A 4 dan A 5 Arduino juga digunakan sebagai pin SDA dan SCL. Gambar 7, merupakan rangkaian LCD, I2C ke Arduino Uno dan Tabel 4, menunjukkan pin LCD dan I2C ke Arduino Uno.

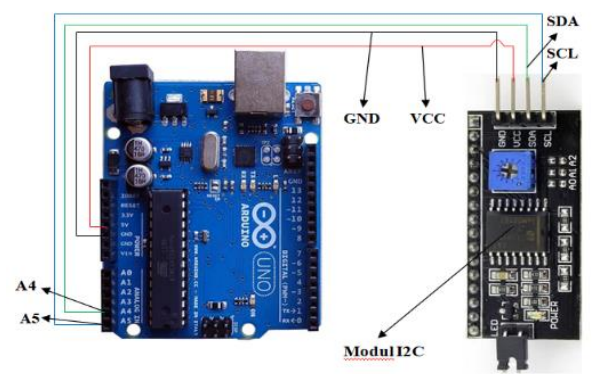

Gambar 7. Rangkaian LCD, I2C ke Arduino Uno

Tabel 4. Pin LCD dan I2C ke Arduino Uno

\begin{tabular}{ll}
\hline Arduino Uno & LCD dan Modul I2C \\
\hline A5 & SCL \\
A4 & SDA \\
$5 \mathrm{~V}$ & VCC \\
GND & GND \\
\hline
\end{tabular}

\section{Modul Relay}

Modul relay berfungsi sebagai pemutus dan penyambung arus pada rangkaian sistem. Modul relay memiliki 3 pin yang dihubungkan dengan Arduino Uno yaitu VCC, GND dan IN. Pin VCC merupakan sumber tegangan $5 \mathrm{~V}$ yang disuplai oleh Arduino Uno, pin GND sebagai grounding dan pin IN merupakan pin digital sebagai penerima perintah dari Arduino Uno. Pin yang dihubungkan aktuator yaitu pin NO, COM dan NC. Pin NO (Normally Open) yaitu pin ketika dalam kondisi normal atau kondisi awalnya terbuka sehingga arus listrik akan mengalir. Pin NC (Normally Close) yaitu pin ketika dalam kondisi normal atau kondisi awalnya tertutup sehingga arus listrik tidak dapat mengalir. Dan pin COM (Common) adalah pin umum atau pin yang harus digunakan supaya modul relay dapat berfungsi, Gambar 8, menunjukkan pin modul relay.

Pemasangan modul relay dan aktuator harus dihubungkan dengan pin COM dan dihubungkan dengan cara memilih salah satu antara pin NO atau pin NC. Jika aktuator dalam kondisi normal membutuhkan arus listrik maka pin yang digunakan adalah pin NO karena aktuator akan lebih sering hidup (on). Sedangkan jika aktuator pada kondisi normal tidak membutuhkan aliran listrik maka pin yang digunakan adalah pin NC karena aktuator akan lebih sering mati (off).

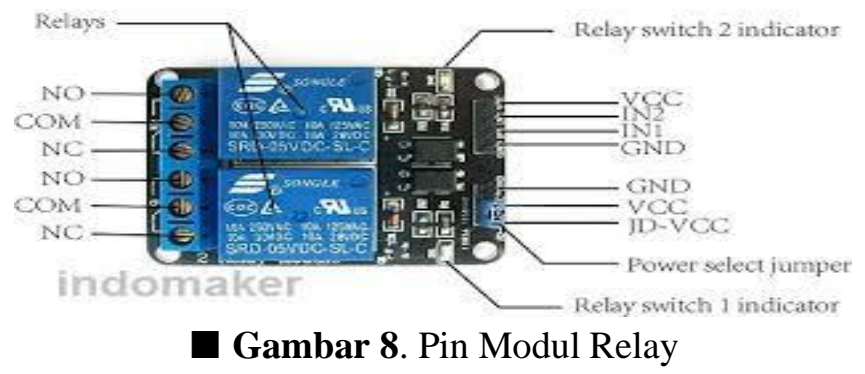

\section{Selenoid Valve}

Solenoid valve diletakkan di bak penampug utama, di bak cairan $\mathrm{pH}$ dan di bak penampung. Solenoid valve berfungsi sebagai keran air input, out put dan keran cairan $\mathrm{pH}$. dengan cara buka tutup katup. Jika solenoid valve terbuka maka air di keran penampung utama mengalir menuju bak penampung, air jernih kemudian dapat digunakan, sedangkan air akan berhenti mengalir jika solenoid valve tertutup. Solenoid 
valve membutuhkan tegangan sebesar $12 \mathrm{~V}$. Arus listrik yang mengalir pada solenoid valve diatur oleh modul relay dan dihubungkan dengan pin NC karena kondisi normal atau kondisi awal solenoid valve adalah mati (off). Gambar 9 adalah rangkaian arduino, relay dan selenoid dan Tabel 4, merupakan konfigurasi pin arduino, relay dan selenoid valve.

Pompa diletakkan di dalam bak penampung yang berfungsi untuk memompa air ke dalam akuarium. Pompa membutuhkan tegangan sebesar $220 \mathrm{~V}$. Arus listrik yang mengalir pada pompa diatur oleh modul relay dan dihubungkan dengan pin NC karena kondisi normal atau kondisi awalnya adalah mati (off). Gambar 10 adalah rangkaian arduino, relay dan pompa air dan Tabel 6, menunjukkan konfigurasi pin arduino, relay dan pompa.

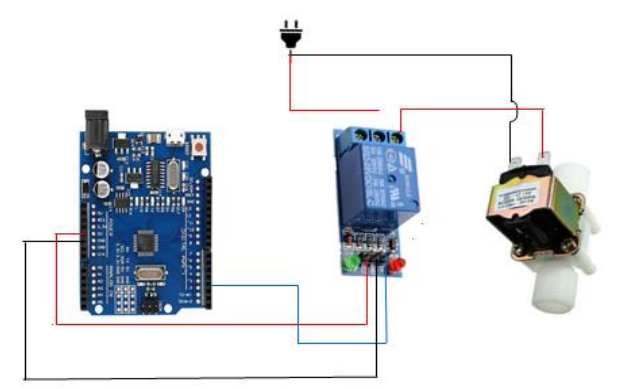

- Gambar 9. Rangkaian Arduino, Relay dan Selenoid

- Tabel 4. Konfigurasi Pin Arduino, Relay dan Selenoid Valve

\begin{tabular}{ll}
\hline Arduino Uno & Selenoid Valve \\
\hline 5V & VCC \\
GND & GND \\
Pin 4 & In1 \\
\hline & \\
&
\end{tabular}

Gambar 10. Rangkaian Arduino, Relay dan Pompa Air

- Tabel 6. Konfigurasi Pin Arduino, Relay dan Pompa

\begin{tabular}{ll}
\hline Arduino Uno & Sensor Ultrasoni \\
\hline VCC & VCC \\
GND & GND \\
Pin 3 & In2 \\
\hline
\end{tabular}

\section{Konfigurasi Keseluruhan Komponen Sistem}

Konfigurasi seluruh komponen sistem merupakan pengujian yang dilakukan setelah semua sistem terkonfigurasi. Konfigurasi tersebut sensor Turbidity dan sensor Ultrasonik sebagai nilai masukan. Solenoid valve sebagai aktuator serta LCD untuk menampilkan karakter. Semua komponen tersebut terkonfigurasi dengan Arduino Uno dengan ditanamkan kode program untuk mengendalikan semua komponen tersebut. Gambar 11 merupakan rangkaian komponen keseluruhan. 


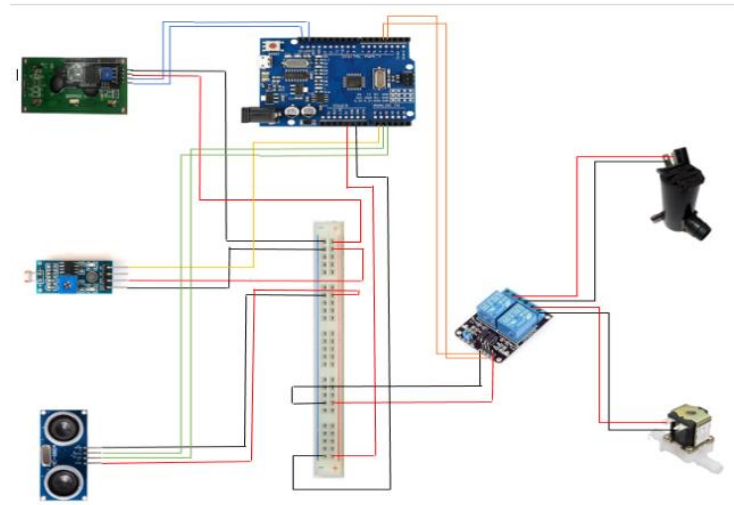

Gambar 11. Rangkaian Komponen Keseluruhan

Dalam pengujian sistem mengukur kekeruhan dan volume air, alat yang sudah jadi diletakkan disuatu tempat yang sudah disediakan dengan dilengkapi sebuah selenoid untuk membuang air dan bak penampung yang berfungsi untuk mengisi air dengan dilengkapi dengan pompa air. Sensor LDR (Light Dependent Resistor) dilengkapi dengan lampu LED yang berwarna putih yang diletakkan didepan sensor LDR (Light Dependent Resistor). Sensor ultrasonic diletakkan diatas permukaan air pada akuarium. Untuk sistem kontrol arduino, serta relay dikemas jadi satu dalam boks projek dan diletakkan didepan. Gambar 12 Hasil Akhir Sistem Keseluruhan.

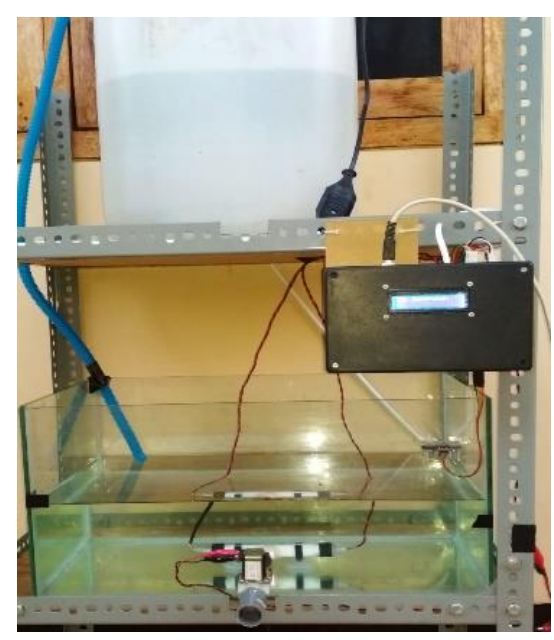

Gambar 12. Hasil Akhir Sistem Keseluruhan

\section{Pengujian Sistem}

Pengujian sistem merupakan tahapan akhir dalam membangun suatu sistem. Pengujian sistem bertujuan untuk mengetahui apakah alat yang dibuat telah sesuai dengan yang direncanakan, hal tersebut dapat diketahui dengan cara mengamati hasil pengujian dan kemudian dianalisa agar dapat diketahui kekurangan dari kinerja sistem yang dibuat. Pengujian sensor cahaya LDR (Light Dependent Resistor) dilakukan dengan cara mengkonfigurasi pin dengan pin Arduino Uno dan menambahkan kode program. Pada pengujian sensor LDR (Light Dependent Resistor) menggunakan air, sumber air yang diambil yaitu pada akuarium. Pengujian rangkaian sensor LDR (Light Dependent Resistor) bertujuan untuk mengetahui ketepatan sensor untuk merespon kekeruhan air. Hasil pengujian rangkaian sensor ini dapat mendeteksi tingkat kekeruhan didalam akuarium. Kemudian memeriksa hasil pembacaan sensor LDR (Light Dependent Resistor) ditampilkan pada LCD. Gambar 13, adalah hasil pengujian sensor LDR, sedangkan Gambar 14 adalah grafik pengujian sensor LDR. Berdasarkan grafik pengujian yang dilakukan diatas pada sensor LDR (Light Dependent Resistor) untuk menentukan nilai kekeruhan dapat disimpulkan pada Tabel 6. 


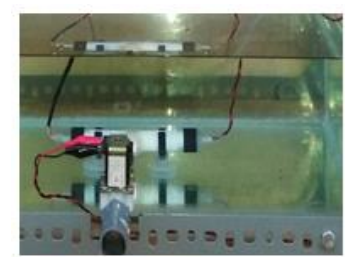

roid $1000(0) 1$

digitalWrite (pinPompaAtas, LON);

digitalwrite (pinPompaBawah, LOW);

kekeruhan $=$ analogRead (pinLDR);

for (; kekeruhan < 110;)

lcd.clear ():

tampillcd (0, "Cek Rekeruhan");

tampilled(1, String (kekeruhan))

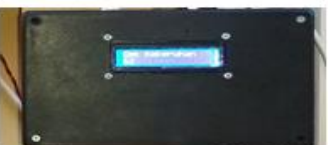

Serial.printin (kekeruhan);

delay (2000):

kekeruhan = analogRead (pinLDR);

Gambar 13. Hasil Pengujian Sensor LDR

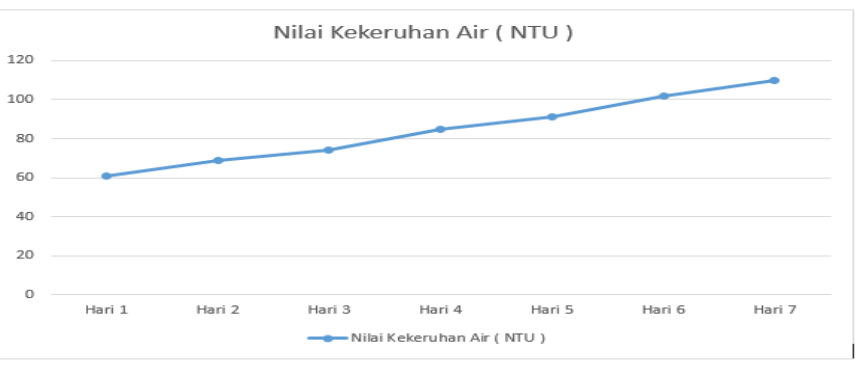

- Gambar 14 Grafik Pengujian Sensor LDR

Berdasarkan grafik pengujian yang dilakukan diatas pada sensor LDR (Light Dependent Resistor) untuk menentukan nilai kekeruhan dapat disimpulkan pada tabel berikut :

Tabel 6. Hasil Nilai Kekeruhan Air

\begin{tabular}{ll}
\hline Jenis Air & Nilai Kekeruhan \\
\hline Air Jernih & $<60$ NTU \\
Air Sedang & $70-100$ NTU \\
Air Keruh & $>110$ NTU \\
\hline
\end{tabular}

Kekeruhan dilihat pada konsentrasi ketidaklarutan, keberadaan partikel pada suatu cairan yang diukur dalam satuan Nephelometric Turbidity Units(NTU). Dari tabel 4.6 dapat dipahami bahwa nilai kekeruhan semakin kecil nilai kekeruhan maka air dinyatakan air jernih dan jika nilai kekeruhan semakin besar maka air dinyatakan air keruh. Hal tersebut dikarenakan LDR (Light Dependent Resistor) merupakan salah satu komponen resistor yang nilai resistansinya akan berubah-ubah sesuai dengan intensitas cahaya yang mengenai sensor ini. LDR juga dapat digunakan sebagai sensor cahaya. Perlu diketahui bahwa nilai resistansi dari sensor ini sangat bergantung pada intensitas cahaya. Semakin banyak cahaya yang mengenainya, maka akan semakin menurun nilai resistansinya. Sebaliknya jika semakin sedikit cahaya yang mengenai sensor (gelap), maka nilai hambatannya akan menjadi semakin besar nilai resistansinya.

Jadi dapat disimpulkan yang terjadi pada akuarium semakin banyak partike-partikel atau sesuatu benda yang menghalangi sensor LDR (Light Dependent Resistor) dan LED maka dinyatakan air tersebut keruh dan jika semakin sedikit partikel-partikel atau suatu benda yang menghalangi sensor LDR (Light Dependent Resistor) dan LED maka dinyatakan air tersebut jernih

\section{Pengujian Sensor Ultrasonik}

Pengujian sensor Ultrasonik dilakukan dengan cara mengkonfigurasi pin sensor Ultrasonik dengan pin Arduino Uno dan menanamkan kode program. Sensor Ultrasonik diletakkan diatas permukaan air pada kolam. Hasill pembacaan akan ditampilkan pada serial monitor yang ada pada aplikasi Arduino Uno. Gambar 15, menunjukkan hasil pengujian sensor ultrasonik. 


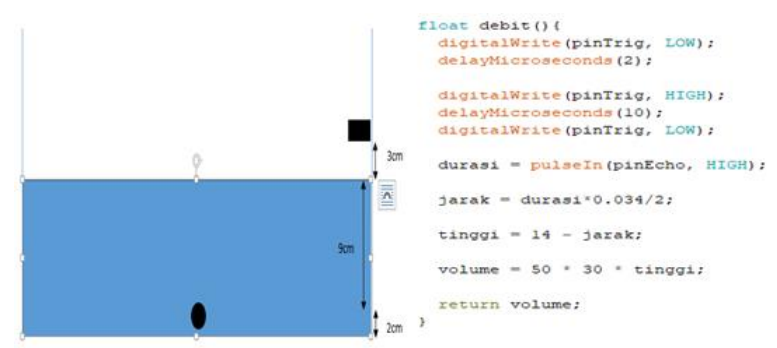

q Gambar 15. Hasil Pengujian Sensor Ultrasonik

Berdasarkan gambar 15 di atas dapat diketahui jarak dari Sensor Ultrasonik sampai dasar kolam = $14 \mathrm{~cm}$, jarak Sensor Ultrasonik sampai batas bawah air $=12 \mathrm{~cm}$, dan jarak Sensor Ultrasonik sampai batas atas air $=3 \mathrm{~cm}$. Dari pernyataan tersebut bisa diketahui tinggi minimum air $14 \mathrm{~cm}-12 \mathrm{~cm}=2 \mathrm{~cm}$, dan tinggi maksimum air $14 \mathrm{~cm}-9 \mathrm{~cm}=11 \mathrm{~cm}$.

Dimana untuk mengukur volume air menggunakan rumus sebagai berikut,

$\mathrm{V}=$ Panjang $\mathrm{x}$ Lebar $\mathrm{x}$ Tinggi

Keterangan :

1. Panjang akuarium $=50 \mathrm{~cm}$

2. Lebar akuarium $=30 \mathrm{~cm}$

Untuk mengetahui volume air maksimal kita harus menghitungnya,

$\mathrm{V}=50 \times 30 \times 11$

$\mathrm{V}=1.500 \times 11$

$\mathrm{V}=16.500 \mathrm{~cm}^{3}$

$\mathrm{L}=16.500: 1000$

$\mathrm{L}=16,5$ liter

Untuk mengetahui volume air minimum kita harus menghitungnya,

$\mathrm{V}=50 \times 30 \times 2$

$\mathrm{V}=1.500 \times 2$

$\mathrm{V}=3.000 \mathrm{~cm}^{3}$

$\mathrm{L}=3.000: 1000$

$\mathrm{L}=3$ liter

Berdasarkan perhitungan di atas dapat diketahui nilai maksimal dan minimal volume air yang ada pada kolam lele. Nilai maksimal volume air adalah 16,5 liter dan nilai minilal volume air adalah 3 liter. Jadi selanjutnya dapat menetapkan nilai batas maksimal dan minimal ke dalam program untuk menjalankan pengurasan dan pengisian air pada kolam lele secara otomatis.

\section{Pengujian Sistem Secara Keseluruhan}

Pengujian terhadap sistem prototype alat pengukur tingkat kekeruhan air dan volume air dilakukan dengan cara menguji sensor Sensor LDR (Light Dependent Resistor) dan sensor Ultrasonik sebagai parameter. Selain pengujian yang dilakukan terhadap parameter tersebut, pengujian juga dilakukan terhadap aktuator. Aktuator yang berfungsi untuk pengendalian sistem secara mekanis antara lain yaitu Pompa dan solenoid valve. Selenoid valve yang digunakan 1 selenoid valve, yang digunakan sebagai kran di akuarium yang berfungsi untuk mengalirkan air keluar, sedangkan pompa digunakan untuk mengisi air kedalam akuarium. Aktuator-aktuator tersebut dikendalikan oleh relay yang berfungsi saklar atau penghubung arus listrik. Serta LCD yang berfungsi untuk menampilkan tulisan/karakter sebagai informasi sistem. Gambar 16, menunjukkan pengujian sistem secara keselruhan, dan Tabel 7, menunjukkan pengujian keseluruhan alat. 


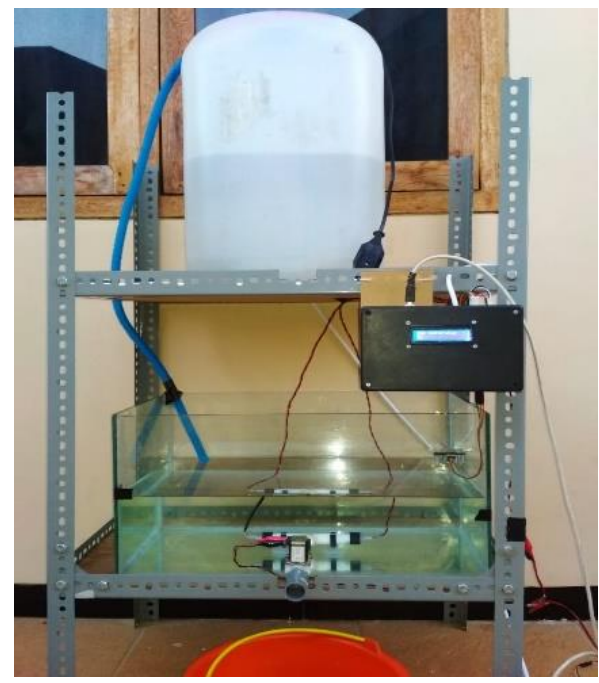

Gambar 16. Pengujian Sistem Secara Keselruhan

Pengujian sistem secara keseluruhan dilakukan dengan cara melihat tingkat kekeruhan yang terdeteksi oleh sensor LDR (Light Dependent Resistor), kemudian bila air sudah mencapai batas dari tingkat kekeruhan yang sudah ditentukan maka air akan mengalir keluar dengan menggunakan selenoid valve yang terhubung ke relay sebagai saklar buka tutup katub di selenoid valve yang ada di aquarium. Bila air sudah terkuras dengan batas minimum selenoid akan tertutup atau mati, dengan mengetahui batas minimum disini ada sensor ultrasonik yang befungsi untuk mengukur batas minimum debit air di aquarium, jika batas minimum air sudah terdeteksi dan selenoid yang ada di aquarium mati maka pompa yang ada di bagian bak penampungan air akan terbuka, dan air yang ada di bak penampung air akan mengalir ke aquarium. Saat air terus mengalir utrasonik ini terus membaca untuk mengukur batas maksimal volume air, sampai batas maksimal air sudah terpenuhi, maka pompa yang ada di bak penampung akan tertutup atau mati dan air yang di aquarium akan terlihat jernih kembali.

- Tabel 7. Pengujian Keseluruhan Alat

\begin{tabular}{llll}
\hline Kekeruhan & Tindakan Alat & Volume Air & Sesuai/Tidak Sesuai \\
\hline 64 & Tidak Sesuai & 16,5 Liter & Sesuai \\
66 & Tidak Sesuai & $16,5 \mathrm{Liter}$ & Sesuai \\
74 & Tidak Sesuai & $16,5 \mathrm{Liter}$ & Sesuai \\
102 & Tidak Sesuai & $16,5 \mathrm{Liter}$ & Tidak Sesuai \\
93 & Tidak Sesuai & $16,5 \mathrm{Liter}$ & Sesuai \\
100 & Tidak Sesuai & $16,5 \mathrm{Liter}$ & Sesuai \\
110 & Selenoid dan Pompa Hidup & $16,5 \mathrm{Liter}$ & Sesuai \\
\hline
\end{tabular}

Berdasakan tabel diatas, maka diperoleh persamaan untuk menghitung akurasi sensor. Berikut ini merupakan perhitungan akurasi sensor :

Persentase error $=$ Niai error $\times 100 \%$

Percobaan

$$
=\frac{(7-6) \times 100 \%}{7}
$$

$$
=14,28 \%
$$

$$
\begin{aligned}
\text { Akurasi Sensor } \quad & =100 \%-14,28 \% \\
& =85,71 \%
\end{aligned}
$$

Keterangan: Nilai eror $=($ hasil percobaan - hasil yang sesuai $)$ 
Berdasarkan perhitungan yang dilakukan untuk menghitung akurasi sensor yang sesuai dengan tabel pengujian yang dilakukan, maka diperoleh nilai akurasi sensor yaitu $85,71 \%$. Secara elektronis rangkaian telah bekerja dengan baik, output dari mikrokontroler dapat mengirimkan data ke LCD. Tampilan LCD dapat menampilkan nilai tingkat kekeruhan dan volume air yang sudah ada. Output pada relay juga sudah bekerja dengan baik sehingga dapat menguras dan mengisi air secara otomatis. Namum alat ini terkendala dengan sensor LDR (Light Dependent Resistor) yang harus ditaruh didasar akuarium yang kemunkinan terjadi kebocoran terhadap sensor LDR (Light Dependent Resistor) yang sudah dimodifikasi, sehingga sensor LDR (Light Dependent Resistor) tersebut kurang baik untuk mengukur tingkat kekeruhan pada akuarium. Bisa juga kendalanya pada lampu LED yang mati sehingga sensor LDR (Light Dependent Resistor) tidak bekerja dengan baik untuk mengukur tingkat kekeruhan yang ada pada akuarium.

\section{KESIMPULAN DAN SARAN}

Berdasarkan penelitian yang telah dilakukan dalam merancang dan membangun sistem prototype alat pendeteksi kekeruhan dan tinggi air pada kolam ikan berbasis mikrokontroler, maka dapat diambil kesimpulan sebagai berikut :

1. Sensor LDR (Light Dependent Resistor) pada sistem prototype pendeteksi kekeruhan air yang sudah terintegrasi dengan Arduino Uno yang tertanam kode program dapat digunakan untuk membaca nilai Kekeruhan air. Nilai yang terbaca pada sensor LDR (Light Dependent Resistor) air keruh $>110$ NTU, air sedang 70-100 NTU, dan air jernih 40-60 NTU.

2. Sensor Ultrasonik pada sistem prototype mengukur volume air yang sudah terintegrasi dengan Arduino Uno yang tertanam kode program dapat digunakan untuk mengukur nilai makimal dan minimal volume air pada kolam lele. Nilai yang terbaca pada sesnor ultrasonik saat pengujian adalah batas maksimal volume air 16,5 liter sedangkan batas minimal volume air 3 liter.

Penelitian yang telah dilakukan tidak lepas dari kekurangan dan kelemahan, oleh karena itu untuk pengembangan sistem lebih lanjut diperlukan perhatian terhadap beberapa hal, diantaranya:

1. Untuk pembuatan alat kekeruhan air dengan model lain sebaiknya lebih memperhatikan masukan dari sumber yang lain, agar alat menjadi lebih sempurna. Dan juga memperhatikan komponen alat yan dipakai sehingga alat bisa dibuat dengan harga yang lebih terjangkau.

2. Agar air tidak terbuang secara percuma alangkah baiknya perlu adanya proses filtrasi air keruh, sehingga air yang keruh menjadi bersih dan dapat digunakan kembali.

\section{DAFTAR PUSTAKA}

[1] Hidayat, Dayat, "Pelatihan Kewiraushaan Budidaya Ikan lele Dumbo untuk Pemberdayaan Pemuda di Desa Kemiri Kecamatan Jayakerta Kabupaten Karawang”, Program Studi Pendidikan Luar Sekolah, Fakultas Keguruan dan Ilmu Pendidikan, Universitas Singaperbangsa Karawang, Vol.1, No.1, April 2017.

[2] Sudana, SN,; Arga, IW,; Suparta, N, "Kelayakan Usaha Budidaya Ikan Lele Dumbo (Clarias gariepinus) dan Pengaruhnya terhadap Tingkat Pendapatan Petani Ikan Lele di Kabupaaten Tabanan", Program Studi Magister Agribisnis, Program Pascasarjana, Fakultas Pertanian, Universitas Udayana, Bali, ISSN 2355-0759, Vol.1, No.1, Mei 2013.

[3] Purwanto, Adi dan Moch. Sulhan, "Perancangan Alat Pendeteksi Tingkat kekeruhan Air pada Kamar Mandi Berbasis Mikrokontroler atmega 8535", Teknik Infomatika, Sitem Informatika, Universitas Kanjuruhan Malang, 2015.

[4] Ramadhan, Muhammad Syarif dan Muhammad Rivai. 2018, "Sistem Kontrol Tingkat Kekeruhan pada Aquarium Menggunakan Arduino Uno", Departemen Teknik Elektro, Fakultas Elektro, Institut Teknologi Sepuluh November, Surabaya, ISSN 2337-3520, Vol.7, No.1, 2018.

[5] Jawas, Hilmy,; N.M.A.E.D.Wirastuti, dan Widyadi Setiawan, "Prototype Pengukuran Tinggi Debit Air pada Bendung dengan Menggunakan Sensor Ultrasonik Berbasis Arduino Mega 2560”, Program Studi Teknik Elektro, Fakultas Teknik, Universitas Udayana. Bali, Vol.5, No.1, Juni 2018.

[6] Setiawan, Desi,; Ishak dan Iskandar Zulkarnaen, "Prototype Alat Pemantauan Ketinggian Air pada Bendungan Menggunakan Sensor Ultrasonik Berbasis Arduino”, Program Studi Komputer, STMK Triguna Dharma, P-ISSN 1978-6603, E-ISSN 2615-3475, Vol.17, No.2 Agustus 2018. 